ARTICLE

Received 1 Jun 2012 | Accepted 8 Nov 2012 | Published 11 Dec 2012

DOI: $10.1038 /$ ncomms2272

OPEN

\title{
Cambrian lobopodians and extant onychophorans provide new insights into early cephalization in Panarthropoda
}

\author{
Qiang Ou', Degan Shu ${ }^{1,2} \&$ Georg Mayer ${ }^{3}$
}

Cambrian lobopodians are important for understanding the evolution of arthropods, but despite their soft-bodied preservation, the organization of the cephalic region remains obscure. Here we describe new material of the early Cambrian lobopodian Onychodictyon ferox from southern China, which reveals hitherto unknown head structures. These include a proboscis with a terminal mouth, an anterior arcuate sclerite, a pair of ocellus-like eyes and branched, antenniform appendages associated with this ocular segment. These findings, combined with a comparison with other lobopodians, suggest that the head of the last common ancestor of fossil lobopodians and extant panarthropods comprized a single ocular segment with a proboscis and terminal mouth. The lack of specialized mouthparts in $O$. ferox and the involvement of non-homologous mouthparts in onychophorans, tardigrades and arthropods argue against a common origin of definitive mouth openings among panarthropods, whereas the embryonic stomodaeum might well be homologous at least in Onychophora and Arthropoda.

\footnotetext{
${ }^{1}$ Early Life Evolution Laboratory, School of Earth Sciences and Resources, China University of Geosciences, Beijing 100083, China. ${ }^{2}$ Department of Geology, State Key Laboratory of Continental Dynamics, Early Life Institute, Northwest University, Xi'an 710069, China. ${ }^{3}$ Animal Evolution and Development, Institute of Biology, University of Leipzig, Talstrasse 33, D-04103 Leipzig, Germany. Correspondence and requests for materials should be addressed to Q.O. (email: ouqiang@cugb.edu.cn) or to G.M. (email: gmayer@onychophora.com).
} 
$\mathrm{T}$ he great diversity of arthropod body plans is reflected by the manifold architecture of their heads. This diversity might have its origins in the early Cambrian or even PreCambrian periods ${ }^{1-3}$, when the three major groups of Panarthropoda diverged: Onychophora (velvet worms), Tardigrada (water bears) and Arthropoda (spiders, centipedes, insects and alike). The trunk anatomy of the last common ancestor of panarthropods most likely resembled that of fossil lobopodians, which share with extant onychophorans and tardigrades a homonomous body segmentation, a soft cuticle without an exoskeleton, and unjointed limbs called lobopods ${ }^{4-7}$. Despite these similarities, the structure and composition of the head among the extant panarthropods are so diverse that it is hard to believe that their heads have a common evolutionary origin. A closer look at the head morphology in fossil lobopodians, thus, might help to unravel the early steps in the diversification of panarthropod heads. So far, however, little is known about the head structure in these ancient animals, mostly because of an incomplete preservation of their anterior ends ${ }^{8-14}$.

We therefore analysed exceptionally preserved specimens of the lower Cambrian lobopodian Onychodictyon ferox ${ }^{15}$ and compared its head anatomy with that in other lobopodians and extant panarthropods. In addition, we examined mouth development in the recent onychophoran Euperipatoides rowelli, which sheds new light on the homology of mouth openings among panarthropods.

\section{Results}

Overview. The taxon Lobopodia established by Snodgrass ${ }^{16}$ most likely comprizes a non-monophyletic assemblage $e^{1,4,12,13}$ of stem-group representatives of Panarthropoda, Onychophora, Tardigrada and Arthropoda. The exact phylogenetic position of O. ferox among non-cycloneuralian ecdysozoans is unresolved ${ }^{11-14,17}$.

Emended diagnosis of $\boldsymbol{O}$. ferox. Armoured lobopodian; anterior end (head region) characterized by a bulbous proboscis, a pair of lateral eyes associated with a pair of dorsolateral, feather-like antenniform appendages and an unpaired arcuate sclerite; mouth terminal, succeeded by a buccal tube leading into a pharyngeal bulb followed by a through-gut; trunk consisting of homonomous segments bearing 12 pairs of unjointed walking limbs (lobopods) with paired claws and 10 pairs of dorsal sclerotized plates; trunk posteriorly merges with last leg pair; body wall and all appendages densely annulated and covered by a thin cuticle (no exoskeleton); and long, slender papillae present on trunk, legs and antenniform appendages.

Trunk anatomy in $\boldsymbol{O}$. ferox. The trunk anatomy of the new material of O. ferox (186 specimens; Supplementary Table S1) corresponds with earlier descriptions 15,18 because complete specimens show 10 pairs of sclerotized dorsal plates with thornlike spines and 12 pairs of annulated lobopods, bearing longitudinal rows of papillae and a pair of sickle-like claws (Figs 1 and $2 \mathrm{a}-\mathrm{c}$ ). The bases of the two posterior-most pairs of limbs are in close proximity, and there is no posterior continuation of the trunk. Numerous finger-like papillae, typically with only the imprints of their bases preserved, are arranged in longitudinal rows along the trunk, and ventrally additional rows of more prominent papillae point downwards (Fig. 2a). In contrast to previous descriptions ${ }^{15,18}$ of a 'short, rounded' head ${ }^{15}$, our specimens show a more complex anatomy of the anterior end than hitherto realized (Figs 1 and $2 \mathrm{a}-\mathrm{h}$; Supplementary Figs S1-S6).

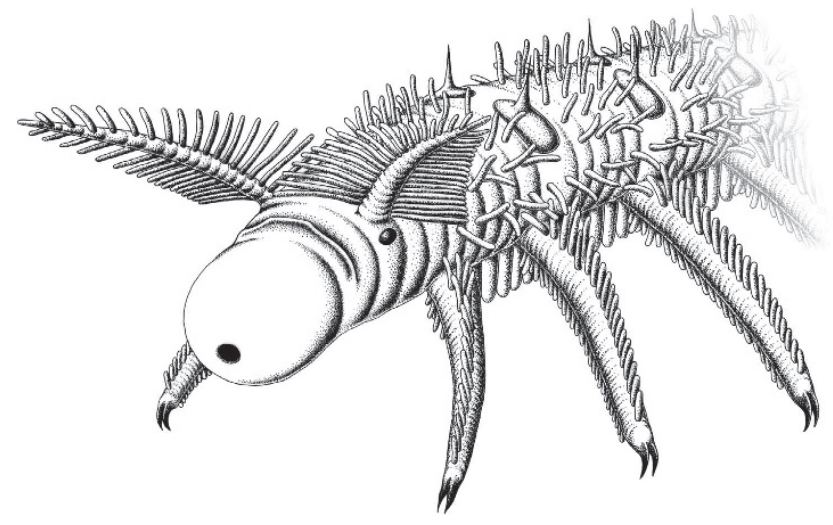

Figure 1 | Anterior body region of the lobopodian $\mathbf{0}$. ferox. Amongst the most conspicuous structures are the feathery, antenniform appendages, the proboscis with a terminal mouth and the ocellus-like eye at the basis of each antenniform appendage.

Head anatomy in $\boldsymbol{O}$. ferox. The new material reveals that the anterior-most portion of the head comprizes a bulbous proboscis, delineated from the rest of the body by a circumferential constriction. A terminal mouth extends into a straight buccal tube (Figs 1 and 2c,f; Supplementary Figs S1-S3). In laterally preserved specimens, the anterior end can be seen to be bent slightly ventrally (Fig. 2a,e-h; Supplementary Figs S1-S4). This accounts for why the proboscis is not seen in specimens preserved in other aspects (Fig. 2b,d; Supplementary Table S1) and, hence, remained undetected in previous studies ${ }^{15,18}$. The proboscis is succeeded by the first body segment, which bears a pair of eyes and antenniform appendages. The eyes are represented by carbonaceous remains of simple, ocellus-like structures situated dorsolaterally on the head. Adjacent to these is a pair of annulated antenniform appendages with numerous branches (Figs 1 and 2c-h; Supplementary Figs S1-S5).

Another prominent feature of the head is a structure posterior to the proboscis, belonging to the first body segment and referred to as the 'arcuate sclerite' (Figs 1 and 2c-f,h; Supplementary Figs $\mathrm{S} 1$, S6). In contrast to the first and the remaining body segments, sclerotized structures of any sort are not evident in the second segment, which bears the first pair of walking lobopods (Figs. 1 and 2c-h; Supplementary Figs S1-S4). A conspicuous feature of this second segment is an internal bulbous structure with an expanded lumen and dark contents, which anteriorly joins the buccal tube and posteriorly the alimentary canal (Fig. 2c; Supplementary Fig. S1). We regard this bulbous structure as a suctorial pharynx on account of its resemblance in position and shape to the pharynx of extant tardigrades and onychophorans $^{19,20}$ (Supplementary Fig. S7).

Mouth development in Onychophora. During embryonic development of the onychophoran E. rowelli, three consecutive mouth openings arise ventrally (Fig. 3a-f). The first mouth occurs anteriorly in the embryonic disc, when the lateral lips of the blastopore close by amphystomy (Fig. 3a). During further development, the ectoderm surrounding this first mouth opening invaginates and forms the second mouth, that is, the stomodaeum, the walls of which eventually give rise to the adult pharyn $^{21-23}$ (Fig. 3b; Supplementary Fig. S7). During stomodaeum development, the orifice of the first (blastoporal) mouth is internalized and, thus, corresponds to the posterior border of the presumptive pharynx (Fig. 3a,f). The stomodaeum is initially located at the border between the first and second body segments (Fig. 3b). As development proceeds, large ectodermal areas surrounding the stomodaeum sink into the embryo-a 

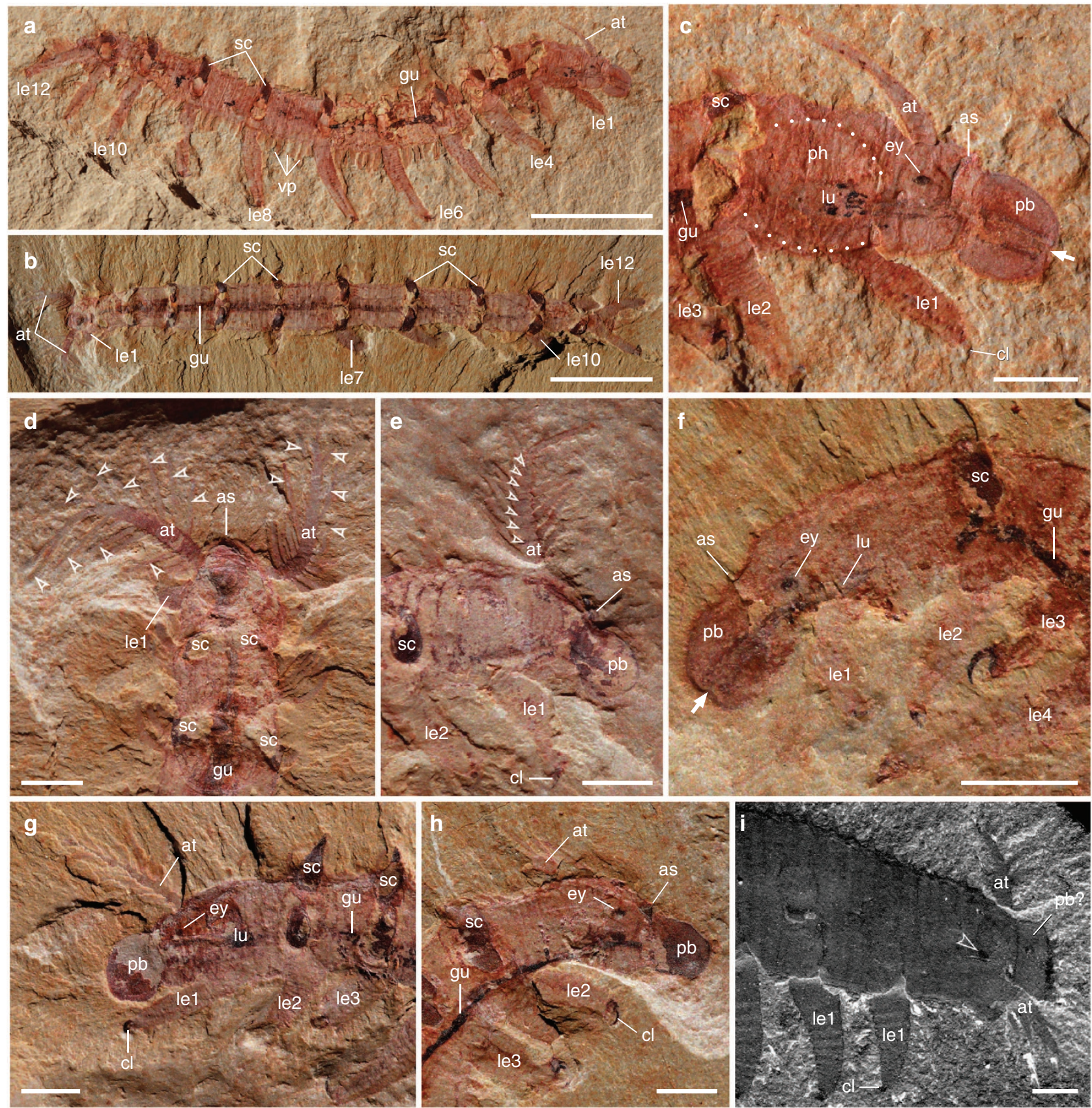

Figure 2 | Anatomy of the lobopodians O. ferox and A. pedunculata. (a-h) O. ferox. (a) Laterally compressed specimen ELEL-SJ101888A; anterior is right. (b) Dorsoventrally compressed specimen ELEL-EJ100329A; anterior is left. (c) Close-up of anterior end in a showing head structures and outline of bulbous pharynx (dotted lines). Arrow points to mouth. (d) Close-up of anterior end in $\mathbf{b}$ showing a pair of branched antenniform appendages (branches indicated by arrowheads). (e) Specimen ELEL-SJ102011A showing left antenniform appendage with branches. Note annulations of antenniform appendage (arrowheads) and claws on first walking lobopod. (f) Specimen ELEL-SJ100307B showing an eye with a lens-like structure. Arrow indicates mouth. (g,h) Specimens ELEL-SJ100635 and ELEL-SJ100546A showing anterior anatomy, notably proboscis, eye and branched antenniform appendages. (i) Anterior end of $A$. pedunculata. Note branched antenniform appendages, eye-like structure (arrowhead) and putative proboscis delineated from the rest of the body. as, arcuate sclerite; at, antenniform appendage; bt, buccal tube; cl, claw; ey, eye; gu, gut; le1-le12, walking lobopods 1-12; lu, pharyngeal lumen; pb, proboscis; ph, pharynx; sc, sclerotized plate; vp, ventral papillae. Scale bars, $1 \mathrm{~cm}$ in $\mathbf{a}$ and $\mathbf{b} ; 2 \mathrm{~mm}$ in $\mathbf{c}-\mathbf{i}$.

process by which the stomodaeum and the anlagen of jaws and tongue are incorporated into the newly formed mouth cavity (Fig. 3c-f). This cavity persists in adults and opens to the exterior via the definitive (third) mouth opening (Fig. 3e; Supplementary Fig. S7). During ontogeny, this mouth opening is formed by an accumulation of lips that originate from the antennal, jaw and slime papilla segments and aggregate around the mouth (Fig. 3c-e). At the end of embryogenesis, the stomodaeum disappears completely within the definitive mouth cavity, and its initial opening corresponds to the anterior border of the presumptive pharynx (Fig. 3d-f; Supplementary Fig. S7).

\section{Discussion}

According to our findings, the paired antenniform appendages of $O$. ferox, which are associated with the ocular segment, differ 

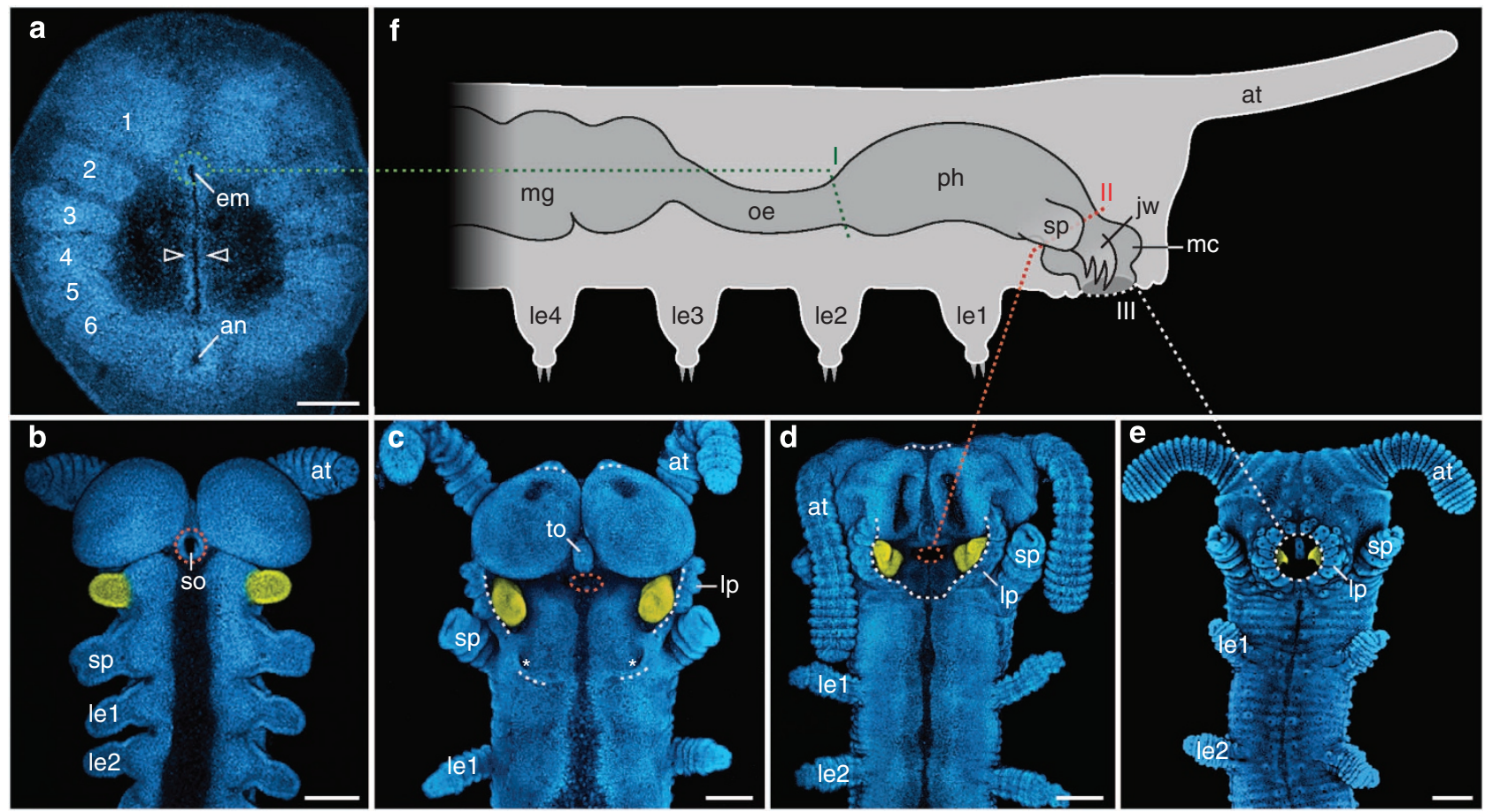

Figure 3 | Mouth development in the onychophoran E. rowelli. Note that three consecutive mouth openings arise during onychophoran ontogeny (indicated by green, red and white dotted lines, respectively). (a-e) Confocal micrographs of embryos at subsequent developmental stages ${ }^{52}$ in ventral view, labelled with the DNA-marker Hoechst as described previously ${ }^{60}$. Anterior is up. Presumptive jaws are coloured artificially in yellow. (a) Embryonic disc of a late stage 1 embryo. Note the first embryonic mouth (em) arising at the anterior end of the slit-like blastopore. Developing segments are numbered. Arrowheads point to closing blastoporal lips. (b) Anterior end of an early stage 4 embryo. Note the position of the stomodaeum (second mouth) at the posterior border of the antennal segment. (c) Anterior end of a late stage 4 embryo. Note the beginning formation of lips that originate from three different segments (white dotted lines). Asterisks indicate openings of presumptive salivary glands. (d) Anterior end of a stage 5 embryo showing the formation of the definitive (third) mouth. Note that the stomodaeum and the anlagen of jaws and tongue are incorporated into the mouth cavity. (e) Anterior end of a stage 7 embryo. Mouth development is completed and lips surround the circular mouth opening. (f) Diagram of an adult onychophoran illustrating regions of digestive tract that correspond to the three consecutive embryonic mouth openings (dotted lines with Roman numerals I-III). Dorsal is up, anterior is right. an, developing anus; at, antenna; em, first embryonic mouth (derivative of the blastopore); jw, jaw; le1-le4, legs 1-4; Ip, developing lips; mc, mouth cavity; mg, midgut; oe, oesophagus; ph, pharynx; so, stomodaeum; sp, slime papilla; to, presumptive tongue. Scale bars, $200 \mu \mathrm{m}$ in a-e.

from walking lobopods in three respects: (i) they lack terminal claws, (ii) they bear on either side slender projections decreasing in length distally and (iii) they have bases that insert dorsolaterally on the ocular segment rather than ventrolaterally. Before this discovery, the identity of the anterior-most pair of appendages in $O$. ferox has remained controversial ${ }^{15,17,18,24}$. An original identification of putative antennae ${ }^{15}$ was then rejected $^{11,18,25}$, but subsequently gained some support ${ }^{17}$. In addition, the anterior-most pair of clawed lobopods were reinterpreted as a pair of modified cephalic appendages ${ }^{18,24}$. Our material, however, shows that the first pair of lobopods do not differ from succeeding pairs and so form a homonomous series of ventral annulated limbs equipped with longitudinal rows of papillae and terminal claws. The pair of antenniform cephalic appendages identified here, thus, lie in front of the first pair of clawed lobopods. Given their location on the ocular segment, we suggest that these appendages are homologous to the branched anterior appendages of Aysheaia pedunculata ${ }^{9}$ (Fig. 2i), the first pair of unbranched antenniform appendages of Antennacanthopodia gracilis $^{26}$, and to the antennae of extant onychophorans ${ }^{23}$.

In contrast, the homology of these appendages with segmental limbs of crown-group arthropods is more difficult to establish because of many divergent views on the composition and evolution of the arthropod heads $5,27-36$. The equivalents of the first pair of appendages might have been lost in extant arthropods because the anterior-most segment in these animals does not show typical modified limbs ${ }^{33,34,37}$. Alternatively, the so-called 'labrum' might be a possible homologue or remnant of this pair of limbs $32,38,39$. However, this view depends on whether the labrum belongs to the first/ocular segment ${ }^{32,33}$, or to the third/intercalary segment $^{27,28}$, or whether it is an independent morphological structure/unit/segment anterior to the eye region ${ }^{29,40}$. Thus, even among the insect species studied, the segmental identity of the labrum is uncertain, not to mention the homology of various structures referred to as a 'labrum' throughout the four major arthropod groups (chelicerates, myriapods, crustaceans and insects). In fact, some authors suggest that a true labrum only exists in the in-group crustacean taxon Labrophora ${ }^{30,31}$. We therefore caution against an uncritical homologization of structures identified as a 'labrum' among crown-group arthropods.

Likewise, the homology of various cephalic appendages across stem-group and crown-group arthropods is controversial. Major inconsistency concerns the so-called 'great appendages', which have been assigned to the first ${ }^{32}$, second ${ }^{5,33-35}$ or third cephalic segments ${ }^{36}$. One of the reasons for the lack of consensus might be insufficient information on head development from fossils. As is well known from work on living arthropods, segmental identities of anterior appendages are difficult to establish without analysing 
gene-expression patterns and details of embryology ${ }^{41,42}$. It seems therefore premature to speculate on the homology of 'great appendages' across panarthropods with complex, composite heads. In contrast, the early cephalization events of stem-group panarthropods might be easier to understand, given the low complexity of their 'heads'. According to our findings, the anterior-most, antenniform appendages of $O$. ferox are homologous to the antennae of onychophorans ${ }^{23,37-39}$. Thus, they can be regarded as 'primary antennae', whereas the equivalents of 'secondary antennae' ( $=$ first antennae of the mandibulate taxa $)^{33}$ in $O$. ferox are unmodified walking limbs.

Ocellus-like visual organs similar to those reported here from specimens of $O$. ferox are found in the coeval lobopodians Miraluolishania haikouensis ${ }^{43}$, Luolishania longicruris ${ }^{12}$ and A. gracilis $^{26}$, as well as extant Onychophora 44 . In addition, ocellus-like structures occur in A. pedunculata ${ }^{9}$ (Fig. 2i) and extant Tardigrada ${ }^{45}$. Evidence from the innervation pattern ${ }^{44}$ and opsins $^{46}$ in Onychophora suggests that simple, ocellus-like eyes are an ancestral feature of Panarthropoda, whereas compound eyes evolved in the arthropod lineage. This hypothesis receives support from the organization of visual organs in fossil lobopodians, given their non-monophyly and phylogenetic position near the basis of the panarthropod tree $2,6,12,13$. We therefore suggest that the eyes of fossil lobopodians and extant onychophorans are homologous and that ocelli were the only type

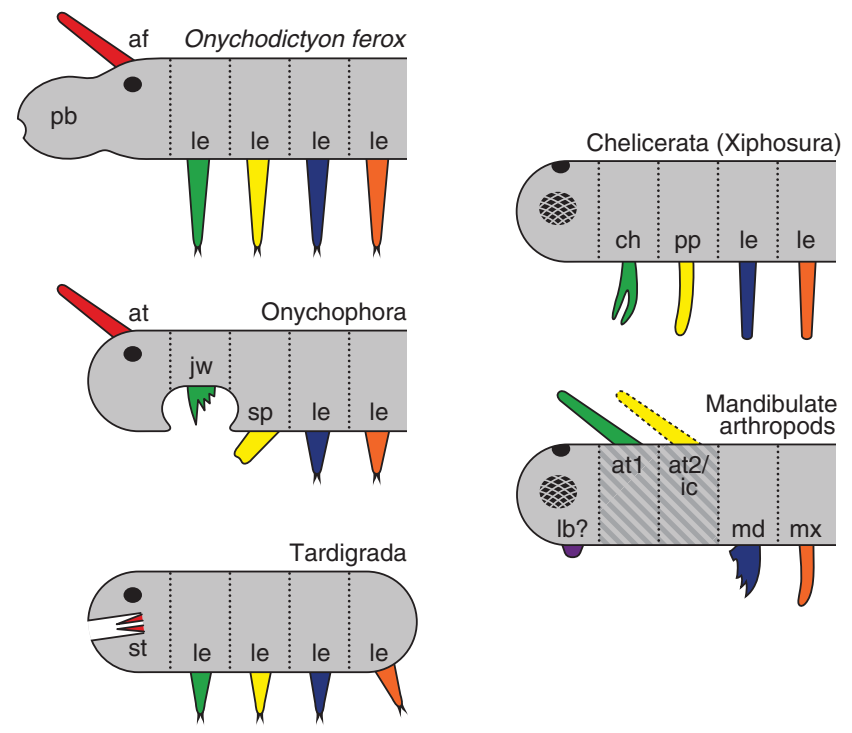

Figure 4 | Alignment and homology of anterior appendages in the lobopodian 0 . ferox and among extant panarthropods. Homologous appendages are depicted by corresponding colour. Vertical dotted lines indicate segmental borders. Black and checked ovals represent ocelli and compound eyes, respectively. Alignment of head segments in tardigrades is based on the assumption of serial homology of the stylet with distal leg portions ${ }^{20}$. Note that segmental identity and homology of the arthropod labrum is discussed controversially $30,31,33,40$. Dark-grey hatched area in the diagram on mandibulate arthropods indicates segments that do not contribute to adult mouth formation. Note that non-homologous segments and structures are involved in adult mouth apparatuses in O. ferox and different groups of extant panarthropods. af, antenniform appendage; at, antenna; at1, first antenna; at2, second antenna (indicated by a dotted line, as it occurs only in crustaceans); ch, chelicera; ic, intercalary segment (limbless in myriapods and hexapods); jw, jaw; lb, labrum (question mark highlights the uncertain segmental identity and homology of this structure); le, walking limbs/lobopods; md, mandible; $\mathrm{mx}$, maxilla; $\mathrm{pb}$, proboscis; pp, pedipalp; sp, slime papilla; st, stylet. of visual organs present in their last common ancestor. These visual organs might have persisted as median ocelli in extant arthropods 44 , whereas subsequent multiplication and modification of these structures gave rise to the ommatidia of compound eyes ${ }^{47,48}$.

The position and near-vertical orientation of the arcuate sclerite in $O$. ferox suggest that this structure might have served as an attachment site for the proboscis musculature. To date, this sclerite has not been reported from other lobopodians and might represent an apomorphy of $O$. ferox. Notably, re-examination of the Burgess Shale lobopodian A. pedunculata reveals what may be a bulbous proboscis, delineated by a constriction (Fig. 2i; Delle Cave and Simonetta ${ }^{8}$ but see Whittington ${ }^{9}$ for an opposed view). Taking into account that lobopodians might be a paraphyletic grade $^{1,4,6,12,13}$ and that $A$. pedunculata is one of the earliestbranching lobopodians 6,12 , we suggest that a non-segmental proboscis with a terminal mouth was present in the last common ancestor of Cambrian lobopodians and extant panarthropods. Whether this structure is homologous to the proboscis of pycnogonids ${ }^{49,50}$ or to the introvert of some cycloneuralians ${ }^{51}$, which also show a terminal mouth, is open for discussion.

Irrespective of this controversy, attempts have been made to homologize the terminal mouth of fossil lobopodians (and cycloneuralians) with the ventral mouth of onychophorans, suggesting that the mouth opening simply migrated to a ventral position in the onychophoran ancestor ${ }^{38}$. However, we have shown here that three different mouth openings arise during onychophoran embryogenesis. This begs the question, which one of these openings can be homologized with the mouths found in other panarthropods. Our data show that the adult onychophoran mouth has a unique ontogenetic fate, as it involves structures that are not found in other animal groups, including lips, tongue and jaws. The lips surrounding the definitive mouth opening originate from the antennal, jaw and slime papilla segments ${ }^{2,22,52}$. Accordingly, the onychophoran mouth is derived from three anterior-most body segments, whereas the mouth of $O$. ferox is proboscideal and, therefore, belongs to a pre-antennal, non-segmental body region (Fig. 4). Our data further revealed no appendage-derived mouthparts in $O$. ferox, whereas onychophorans show a pair of jaws enclosed within a mouth cavity. The jaws are modified limbs of the second body segment, equivalent to the first pair of walking lobopods in O. ferox. On this basis, neither the position (segmental identity) of the adult mouth nor the composition of its cavity indicates homology of mouth apparatuses in onychophorans and O. ferox.

Likewise, owing to the differing positions of the openings and the involvement of different segments, neither the onychophoran nor the $O$. ferox mouths appear to be homologous with the mouth apparatuses in arthropods and tardigrades (Fig. 4). Various arthropods, including pycnogonids, xiphosurans and entomostracan crustaceans, show no specialized mouth chambers with internalized limbs, whereas in myriapods, hexapods and malacostracan crustaceans, the mouth chamber is formed by several pairs of modified appendages, including the mandibles and the maxillae $e^{33,53}$ (the latter are enclosed within an additional pouch of the head capsule in entognathan hexapods). In tardigrades, the stylet within the buccal tube might be a derivative of the distal limb portions ${ }^{20}$, suggesting that at least one pair of segmental appendages has been incorporated into the tardigrade mouth. We therefore interpret the stylet as a derivative of the first pair of segmental appendages, as there is no evidence of any additional segments in the tardigrade head ${ }^{54}$ (Fig. 4). Thus, neither the stylet nor the mandibles or the maxillae belong to segments, which are homologous to the mouth-bearing segments in onychophorans (Fig. 4). Because neither positional nor structural or any other criteria of homology ${ }^{55-57}$ are satisfied when comparing the adult 
mouths in O. ferox, onychophorans and other panarthropods, we suggest that they are not homologous but have divergent evolutionary histories in these animal groups.

In contrast, the embryonic stomodaeum might well be homologous at least in Onychophora and Arthropoda. In both taxa, the stomodaeum arises ventrally in the same position, that is, at the border between the first and second body segments (Supplementary Fig. S8), and it gives rise to the corresponding ectodermal foregut structures ${ }^{21-23,58}$. Although these correspondences in position and ontogenetic fate support the homology of the stomodaeum, from this stage onwards, the morphogenetic processes of mouth development differ fundamentally between Onychophora and Arthropoda, and even between different arthropod groups $31,49,53,58$. Unlike arthropods, the ontogeny of the adult mouth is conserved in Onychophora and, thus, might recapitulate the evolutionary changes that have taken place in the onychophoran lineage. Contrary to the assumption ${ }^{38}$ of a simple ventral migration of the ancestral mouth, we suggest that the mouth cavity of Onychophora has arisen by an invagination of the ectoderm, surrounding an ancestral mouth opening and subsequent incorporation of the second pair of appendages into this cavity. Along with their migration, these appendages were transformed into jaws - a characteristic feature of recent Onychophora. Thus, the definitive mouth of Onychophora is not equivalent to the terminal mouth of Cambrian lobopodians, including O. ferox, and the transformation between the two mouth types can only be understood by finding transitional forms. We therefore believe that the description of detailed head morphologies, as provided herein for $O$. ferox, from additional lobopodians will shed more light on the evolution of complexity and diversity of mouth apparatuses among extant panarthropods and their Cambrian relatives.

\section{Methods}

Specimens of the lobopodian 0. ferox. Specimens of $O$. ferox $(n=186)$ were collected during 2008-2010 from the Heilinpu (previously Qiongzhusi) Formation (Chengjiang fauna, lower Cambrian, $520 \mathrm{Ma}$ ), Yunnan, southern China. Among these specimens, 84 are preserved with proboscis, 34 with mouth opening, 44 with buccal tube, 36 with pharyngeal bulb, 32 with eyes, 95 with antennal rachis, 65 with antennal branches and 114 with arcuate sclerite (Supplementary Table. S1). All specimens are reposited in the Early Life Evolution Laboratory, China University of Geosciences, Beijing, China.

Specimens of E. rowelli and Macrobiotus sp. Specimens of E. rowelli were obtained and handled as described previously ${ }^{59,60}$. Tardigrades (Macrobiotus sp.) were obtained from moss samples collected in the Volkspark Großdeuben (Saxony, Germany) and labelled with phalloidin-rhodamine as described for onychophorans ${ }^{60}$.

Microscopy and image processing. Specimens of the lobopodian O. ferox were photographed using a Canon 5D Mark II digital camera. Details were analysed using a Zeiss Stemi-2000C stereomicroscope (Carl Zeiss MicroImaging GmbH, Jena, Germany), equipped with a Canon 450D digital camera. Specimens of the onychophoran E. rowelli and the tardigrade Macrobiotus sp. were analysed with the confocal laser-scanning microscopes Zeiss LSM 510 META (Carl Zeiss MicroImaging GmbH) and Leica TCS STED (Leica Microsystems, Wetzlar, Germany) Confocal image stacks were processed with Zeiss LSM IMAGE BROWSER v4.0.0.241 (Carl Zeiss MicroImaging GmbH) and Leica AS AF v2.3.5 (Leica Microsystems). Final panels and diagrams were designed with Adobe (San Jose, CA, USA) Photoshop CS4 and Illustrator CS4.

\section{References}

1. Maas, A. \& Waloszek, D. Cambrian derivatives of the early arthropod stem lineage, pentastomids, tardigrades and lobopodians-an 'Orsten' perspective. Zool. Anz. 240, 451-459 (2001).

2. Edgecombe, G. D. Arthropod phylogeny: an overview from the perspectives of morphology, molecular data and the fossil record. Arthropod Struct. Dev. 39, 74-87 (2010).

3. Erwin, D. H. et al. The Cambrian conundrum: early divergence and later ecological success in the Early history of animals. Science 334, 1091-1097 (2011).

4. Budd, G. E. Why are arthropods segmented? Evol. Dev. 3, 332-342 (2001)
5. Waloszek, D., Chen, J., Maas, A. \& Wang, X. Early Cambrian arthropods-new insights into arthropod head and structural evolution. Arthropod Struct. Dev. 34, 189-205 (2005).

6. Edgecombe, G. D. Palaeontological and molecular evidence linking arthropods, onychophorans, and other Ecdysozoa. Evo. Edu. Outreach 2, 178-190 (2009).

7. Maas, A., Mayer, G., Kristensen, R. M. \& Waloszek, D. A Cambrian microlobopodian and the evolution of arthropod locomotion and reproduction. Chin. Sci. Bull. 52, 3385-3392 (2007).

8. Delle Cave, L. \& Simonetta, A. M. Notes on the morphology and taxonomic position of Aysheaia (Onychophora?) and of Skania (undetermined phylum). Monitore Zoologico Italiano 9, 67-81 (1975).

9. Whittington, H. B. The lobopod animal Aysheaia pedunculata Walcott, middle Cambrian, Burgess Shale, British Columbia. Philos. Trans. R. Soc. Lond. B Biol. Sci. 284, 165-197 (1978).

10. Dzik, J. \& Krumbiegel, G. The oldest 'onychophoran' Xenusion: a link connecting phyla? Lethaia 22, 169-181 (1989).

11. Bergström, J. \& Hou, X. G. Cambrian Onychophora or xenusians. Zool. Anz. 240, 237-245 (2001).

12. Ma, X., Hou, X. \& Bergström, J. Morphology of Luolishania longicruris (lower Cambrian, Chengiiang Lagerstätte, SW China) and the phylogenetic relationships within lobopodians. Arthropod Struct. Dev. 38, 271-291 (2009).

13. Liu, J. et al. An armoured Cambrian lobopodian from China with arthropodlike appendages. Nature 470, 526-530 (2011).

14. Dzik, J. The xenusian-to-anomalocaridid transition within the lobopodians. Boll. Soc. Paleontol. Ital. 50, 65-74 (2011).

15. Ramsköld, L. \& Hou, X. New early Cambrian animal and onychophoran affinities of enigmatic metazoans. Nature 351, 225-228 (1991).

16. Snodgrass, R. E. Evolution of the Annelida, Onychophora and Arthropoda. Smithson. Misc. Coll. 97, 1-159 (1938).

17. Liu, J., Shu, D., Han, J., Zhang, Z. \& Zhang, X. The lobopod Onychodictyon from the lower Cambrian Chengjiang Lagerstätte revisited. Acta Palaeontol. Pol. 53, 285-292 (2008).

18. Ramsköld, L. \& Chen, J. in Arthropod Fossils Phylogeny (ed. Edgecombe, G. D.) 107-150 (Columbia University Press, 1998).

19. Schmidt-Rhaesa, A., Bartolomaeus, T., Lemburg, C., Ehlers, U. \& Garey, J. R. The position of the Arthropoda in the phylogenetic system. J. Morphol. 238, 263-285 (1998).

20. Halberg, K. A., Persson, D., Møbjerg, N., Wanninger, A. \& Kristensen, R. M. Myoanatomy of the marine tardigrade Halobiotus crispae (Eutardigrada: Hypsibiidae). J. Morphol. 270, 996-1013 (2009).

21. von Kennel, J. Entwicklungsgeschichte von Peripatus edwardsii Blanch. und Peripatus torquatus n. sp. II. Theil. Arb. Zool.-Zootom. Inst. Würzburg 8, 1-93 (1888).

22. Mayer, G., Bartolomaeus, T. \& Ruhberg, H. Ultrastructure of mesoderm in embryos of Opisthopatus roseus (Onychophora, Peripatopsidae): revision of the 'long germ band' hypothesis for Opisthopatus. J. Morphol. 263, 60-70 (2005).

23. Mayer, G. \& Koch, M. Ultrastructure and fate of the nephridial anlagen in the antennal segment of Epiperipatus biolleyi (Onychophora, Peripatidae)evidence for the onychophoran antennae being modified legs. Arthropod Struct. Dev. 34, 471-480 (2005).

24. Ramsköld, L. Homologies in Cambrian Onychophora. Lethaia 25, 443-460 (1992).

25. Hou, X.-G. et al. The Cambrian Fossils of Chengjiang, China. The Flowering of Early Animal Life (Blackwell Publishing, 2004).

26. Ou, Q. et al. A rare onychophoran-like lobopodian from the lower Cambrian Chengjiang Lagerstätte, Southwest China, and its phylogenetic implications. J. Paleontol. 85, 587-594 (2011).

27. Haas, M. S., Brown, S. J. \& Beeman, R. W. Pondering the procephalon: the segmental origin of the labrum. Dev. Genes Evol. 211, 89-95 (2001).

28. Boyan, G. S., Williams, J. L. D., Posser, S. \& Bräunig, P. Morphological and molecular data argue for the labrum being non-apical, articulated, and the appendage of the intercalary segment in the locust. Arthropod Struct. Dev. 31, 65-76 (2002).

29. Urbach, R. \& Technau, G. M. Early steps in building the insect brain neuroblast formation and segmental patterning in the developing brain of different insect species. Arthropod Struct. Dev. 32, 103-123 (2003).

30. Siveter, D. J., Waloszek, D. \& Williams, M. An early Cambrian phosphatocopid crustacean with three-dimensionally preserved soft parts from Shropshire, England. Special Papers in Palaeontology 70, 9-30 (2003).

31. Liu, Y., Maas, A. \& Waloszek, D. Early development of the anterior body region of the grey widow spider Latrodectus geometricus Koch, 1841 (Theridiidae, Araneae). Arthropod Struct. Dev. 38, 401-416 (2009).

32. Budd, G. E. A palaeontological solution to the arthropod head problem. Nature 417, 271-275 (2002).

33. Scholtz, G. \& Edgecombe, G. D. The evolution of arthropod heads: reconciling morphological, developmental and palaeontological evidence. Dev. Genes Evol. 216, 395-415 (2006). 
34. Scholtz, G. \& Edgecombe, G. D. in Crustacea and Arthropod Phylogeny (eds Koenemann, S., Jenner, R. \& Vonk, R.) 139-165 (CRC Press, 2005).

35. Chen, J., Waloszek, D. \& Maas, A. A new 'great appendage' arthropod from the lower Cambrian of China and homology of chelicerate chelicerae and raptorial antero-ventral appendages. Lethaia 37, 3-20 (2004).

36. Cotton, T. J. \& Braddy, S. J. The phylogeny of arachnomorph arthropods and the origin of the Chelicerata. Trans. R Soc. Edinb. Earth Sci. 94, 169-193 (2004).

37. Mayer, G., Whitington, P. M., Sunnucks, P. \& Pflüger, H.-J. A revision of brain composition in Onychophora (velvet worms) suggests that the tritocerebrum evolved in arthropods. BMC Evol. Biol. 10, 255 (2010).

38. Eriksson, B. J. \& Budd, G. E. Onychophoran cephalic nerves and their bearing on our understanding of head segmentation and stem-group evolution of Arthropoda. Arthropod Struct. Dev. 29, 197-209 (2000).

39. Eriksson, B. J., Tait, N. N., Budd, G. E., Janssen, R. \& Akam, M. Head patterning and Hox gene expression in an onychophoran and its implications for the arthropod head problem. Dev. Genes Evol. 220, 117-122 (2010).

40. Posnien, N., Bashasab, F. \& Bucher, G. The insect upper lip (labrum) is a nonsegmental appendage-like structure. Evol. Dev. 11, 480-488 (2009).

41. Damen, W. G. M., Hausdorf, M., Seyfarth, E. A. \& Tautz, D. A conserved mode of head segmentation in arthropods revealed by the expression pattern of Hox genes in a spider. Proc. Natl Acad. Sci. USA 95, 10665-10670 (1998).

42. Jager, M. et al. Homology of arthropod anterior appendages revealed by Hox gene expression in a sea spider. Nature 441, 506-508 (2006).

43. Liu, J., Shu, D., Han, J. \& Zhang, Z. A rare lobopod with well-preserved eyes from Chengiiang Lagerstätte and its implications for origin of arthropods. Chin. Sci. Bull. 49, 1063-1071 (2004).

44. Mayer, G. Structure and development of onychophoran eyes-what is the ancestral visual organ in arthropods? Arthropod Struct. Dev. 35, 231-245 (2006).

45. Greven, H. Comments on the eyes of tardigrades. Arthropod Struct. Dev. 36, 401-407 (2007)

46. Hering, L. et al. Opsins in Onychophora (velvet worms) suggest a single origin and subsequent diversification of visual pigments in arthropods. Mol. Biol. Evol. 29, 3451-3458 (2012).

47. Bitsch, C. \& Bitsch, J. in Crustaceans and Arthropod Relationships (ed. Koenemann, S.) 81-111 (CRC Press, Taylor \& Francis Book Inc., 2005).

48. Land, M. F. \& Nilsson, D.-E. Animal Eyes 2nd edn. (Oxford University Press (2012).

49. Vilpoux, K. \& Waloszek, D. Larval development and morphogenesis of the sea spider Pycnogonum litorale (Ström, 1762) and the tagmosis of the body of Pantopoda. Arthropod Struct. Dev. 32, 349-383 (2003).

50. Dunlop, J. A. \& Arango, C. P. Pycnogonid affinities: a review. J. Zool. Sys. Evol. Res. 43, 8-21 (2005)

51. Nielsen, C. Animal Evolution: Interrelationships of the Living Phyla 3rd edn. (Oxford University Press (2012).

52. Walker, M. H. \& Tait, N. N. Studies on embryonic development and the reproductive cycle in ovoviviparous Australian Onychophora (Peripatopsidae). J. Zool. 264, 333-354 (2004)

53. Ungerer, P. \& Wolff, C. External morphology of limb development in the amphipod Orchestia cavimana (Crustacea, Malacostraca, Peracarida). Zoomorphology 124, 89-99 (2005).
54. Gabriel, W. N. \& Goldstein, B. Segmental expression of Pax3/7 and Engrailed homologs in tardigrade development. Dev. Genes Evol. 217, 421-433 (2007).

55. Remane, A. Die Grundlagen des natürlichen Systems, der vergleichenden Anatomie und der Phylogenetik. Theoretische Morphologie und Systematik (Akademische Verlagsgesellschaft Geest \& Portig, 1952).

56. Patterson, C. in Problems of phylogenetic reconstruction (eds Joysey, K. A. \& Friday, A. E.) 21-74 (Academic Press, 1982).

57. Richter, S. Homologies in phylogenetic analyses-concept and tests. Theory Biosci. 124, 105-120 (2005).

58. Anderson, D. T. Embryology and Phylogeny in Annelids and Arthropods (Pergamon Press, 1973).

59. Mayer, G. \& Whitington, P. M. Velvet worm development links myriapods with chelicerates. Proc. R. Soc. B Biol. Sci. 276, 3571-3579 (2009).

60. Mayer, G. \& Whitington, P. M. Neural development in Onychophora (velvet worms) suggests a step-wise evolution of segmentation in the nervous system of Panarthropoda. Dev. Biol. 335, 263-275 (2009).

\section{Acknowledgements}

This work was supported by grants from the National Natural Science Foundation of China (No. 41102012, Shaanxi-2011JZ006) to D.S. and Q.O., the Fundamental Research Funds for the Central Universities (2010ZY07, 2011YXL013 and 2012097) to Q.O., and the German Research Foundation (DFG, Ma 4147/3-1) to G.M. G.M. is a Research Group Leader supported by the Emmy Noether Programme of the DFG. We thank the staff of Forests NSW (New South Wales, Australia) for providing collecting permits. We are thankful to Paul Sunnucks and Noel Tait for their help with collecting the onychophorans, to Susann Kauschke and Jan Rüdiger for labelling the tardigrades, to Xingliang Zhang and Jianni Liu for providing the images of A. pedunculata and to Simon Conway Morris for providing helpful comments on the first draft of our manuscript.

\section{Author contributions}

Q.O. collected and prepared specimens of the lobopodian O. ferox. G.M. handled specimens of the onychophoran E. rowelli and the tardigrade Macrobiotus sp. and prepared the ink reconstruction of O. ferox. G.M. and Q.O. analysed the data and wrote the paper. All authors discussed the results and prepared the final manuscript.

\section{Additional information}

Supplementary Information accompanies this paper at http://www.nature.com/ naturecommunications

Competing financial interests: The authors declare no competing financial interests

Reprints and permission information is available online at http://npg.nature.com/ reprintsandpermissions/

How to cite this article: Ou, Q. et al. Cambrian lobopodians and extant onychophoran provide new insights into early cephalization in Panarthropoda. Nat. Commun. 3:1261 doi: $10.1038 /$ ncomms2272 (2012).

(c) (1) $\odot$ This work is licensed under a Creative Commons AttributionNonCommercial-NoDerivs 3.0 Unported License. To view a copy of this license, visit http://creativecommons.org/licenses/by-nc-nd/3.0/ 